\title{
BMJ Open The relation between birthweight, childhood body mass index, and overweight and obesity in late adolescence: a longitudinal cohort study from Norway, The Tromsø Study, Fit Futures
}

Elin Evensen, ${ }^{1}$ Nina Emaus, ${ }^{2}$ Ane Kokkvoll, ${ }^{3,4}$ Tom Wilsgaard, ${ }^{1,5}$ Anne-Sofie Furberg, ${ }^{5,6}$ Guri Skeie ${ }^{5}$

To cite: Evensen E, Emaus N, Kokkvoll A, et al. The relation between birthweight, childhood body mass index, and overweight and obesity in late adolescence: a longitudinal cohort study from Norway, The Troms $\emptyset$ Study, Fit Futures. BMJ Open 2017;7:e015576. doi:10.1136/ bmjopen-2016-015576

- Prepublication history and additional material are available. To view these files please visit the journal online (http://dx.doi. org/10.1136/bmjopen-2016015576).

Received 18 December 2016 Revised 10 March 2017 Accepted 3 April 2017

CrossMark

For numbered affiliations see end of article.

Correspondence to

Elin Evensen; elin.evensen@ unn.no

\section{ABSTRACT}

Objectives Childhood overweight/obesity is associated with later overweight/obesity. However, the association between birth weight and later overweight/obesity has not been established. The aim of this study was to investigate the relation between both birth weight and childhood body mass index (BMI), and adolescent overweight/obesity in a Norwegian population.

Methods The Troms $\emptyset$ Study - Fit Futures is a population-based cohort study conducted in 2010-2011 and 2012-2013 in Tromsø, Norway. A representative sample of 961 adolescents participated. Longitudinal anthropometric data were obtained from the Medical Birth Registry of Norway, childhood health records at 2-4 and 5-7 years of age, and repeated measurements at 15-18 and 18-20 years of age. Outcome was defined as normal weight (adult BMI $<25 \mathrm{~kg} / \mathrm{m}^{2}$ ) or overweight/ obese (adult BMI $\geq 25 \mathrm{~kg} / \mathrm{m}^{2}$ ) at $15-20$ years of age according to international age- and sex-specific cut-off values for children. Associations were investigated using generalised estimating equations.

Results In adjusted analyses, a 1-SD (586 g) higher birth weight was associated with a higher OR for overweight/obesity at 15-20 years of age (OR 1.25, 95\% $\mathrm{Cl} 1.06$ to 1.48). Childhood BMI was also associated with overweight/obesity at 15-20 years of age: a 1-SD $\left(1.35 \mathrm{~kg} / \mathrm{m}^{2}\right)$ increase in BMl at age 2-4 years rendered an OR of 1.66 (95\% Cl 1.40 to 1.96$)$; a $1-S D(1.83 \mathrm{~kg} /$ $\left.\mathrm{m}^{2}\right)$ increase in BMl at age 5-7 years rendered an OR of 3.23 (95\% Cl 2.56 to 4.07$)$. When compared with normal-weight children, those with severe overweight/ obesity in childhood (adult BMI $\geq 27 \mathrm{~kg} / \mathrm{m}^{2}$ ) showed stronger associations with overweight/obesity at 15-20 years of age: OR $3.01(95 \% \mathrm{Cl} 1.47$ to 6.18$)$ and $\mathrm{OR}$ 11.51 (95\% Cl 6.63 to 19.99) at ages $2-4$ and 5-7, respectively.

Conclusion Associations between birth weight and overweight/obesity at 15-20 years of age were modest, whereas the influence of BMI at 2-4 and 5-7 years on overweight/obesity at 15-20 years was moderate to strong.
Strengths and limitations of this study

- The main strengths of this study are its populationbased design and access to longitudinal data from birth (1992-1994 cohort) to 18-20 years of age.

- The high attendance rate and representative sample from a Norwegian adolescent population minimise selection bias.

- Data from the national Medical Birth Registry of Norway and objectively measured height and weight were used to calculate body mass index at all ages, reducing the risk of information bias.

- Missing data from childhood measurements were handled with a multiple imputation technique.

- A limitation of this study is the lack of information on potential confounding factors such as parental and lifestyle factors at birth and childhood.

\section{INTRODUCTION}

The increasing prevalence of overweight/ obesity among children worldwide is a major health concern due to several related immediate and long-term health problems. ${ }^{1-7} \mathrm{~A}$ moderate degree of tracking (maintenance of certain risk factors over time) has been reported from childhood to adolescence and into adulthood, indicating that individuals experience only small changes in weight class positions throughout their life. ${ }^{689}$ However, the question remains whether birth weight is a predictor of later overweight/obesity. In a review by Brisbois et $a l^{10}$, birth weight did not emerge as an early marker for adult overweight/obesity, but a recent review reported consistent associations between high birth weight and overweight later in childhood. ${ }^{11}$ Data from Norway also revealed strong associations between birth 
weight and overweight/obesity at 7-8 years of age. ${ }^{12} 13$ From a health perspective, it is of interest to investigate whether high birth weight also tracks into adolescence/ early adulthood.

Lately, the focus of this investigation has shifted to early-life factors, especially genetic factors that influence obesity and later health problems. ${ }^{14-16}$ Information on the degree of tracking of high birth weight and body mass index (BMI) during early childhood is important for health authorities and healthcare workers who are planning preventive interventions to halt the overweight epidemic. Effective treatment of childhood obesity has proven to be very challenging ${ }^{17}$; therefore preventive efforts are of major importance. However, the appropriate age at which to initiate such efforts is still a matter of discussion. ${ }^{14}$

To answer these questions, we aimed to explore the associations between both birth weight and childhood BMI and overweight/obesity in adolescence in a population-based cohort of Norwegian adolescents born in 1992-1994, a period with high mean birth weight in Norway. ${ }^{18}$

\section{METHODS}

Fit Futures is an expansion of The Tromsø Study, a population-based study from Northern Norway with repeated health surveys among adults. All first-year students in all upper-secondary schools in the municipalities of Troms $\varnothing$ and Balsfjord in 2010-2011 ( $\mathrm{n}=1117)$ were invited to Fit Futures 1 (FF1). Of these invited students 1038 (92.9\%) attended. Detailed information on FF1 and its youth cohort has already been presented. ${ }^{19}{ }^{20}$ A follow-up study, Fit Futures 2 (FF2), was conducted 2 years later during 2012-2013, and re-invited all participants from FF1. The present study consists of the 961 participants (492 boys and 469 girls) in FF1 who were aged $<18$ years at FF1 (born 1992-1994). Among these, 659 had anthropometric measurements available at $18-20$ years of age in FF2.

Longitudinal anthropometric data were obtained through linkage to the Medical Birth Registry of Norway (MBRN) and childhood health records. Each student's unique personal identification number was used to link to the MBRN, from which information on birth weight and length, gestational age, and other variables related to birth were obtained. Height, weight, age, and date of measurements at two time points were collected from childhood health records. In Norway, regular health controls by public health nurses, including measurement of height and weight, are offered for all children in accordance with national preventive health programme guidelines. Most of our participants had their height and weight measured at 2 and 6 years of age. If data were missing for those exact ages or there were supplementary measurements, the measurement closest to the 2- and 6 -year birthday was recorded. The exact age of the participants at the time measurements were taken varied slightly; therefore the age groups are reported as $2-4$ (mean age 2.6 years) and $5-7$ years of age (mean age 6.0 years).

A total of 411 included participants $(43 \%)$ had one or more variables missing from the MBRN and/or childhood health records (5\% missing birth weight, $29 \%$ and $23 \%$ missing height/weight at 2-4 and 5-7 years of age, respectively). Reasons for missing the childhood measurements were change of residency and measurements outside the age limits. Three hundred and two $(31 \%)$ participants had missing data at FF2. A flow chart shows the study population and exclusions/missing information (figure 1).

The Regional Committee for Medical and Health Research Ethics, North Norway (REK nord) approved FF1, FF2 and the present study (Reference number: 2014/1397/REK nord). All students and parents/guardians of students $<16$ years of age gave written informed consent.

\section{Data/measurements}

Trained study nurses performed anthropometric measurements in FF1 and FF2, following standardised procedures. Participants wore light clothing and no footwear. Height and weight were measured to the nearest $0.1 \mathrm{~cm}$ and $0.1 \mathrm{~kg}$, respectively, on an automatic electronic scale/stadiometer (Jenix DS 102 stadiometer, Dong Sahn Jenix, Seoul, Korea) at FF1 (15-17 years of age; mean age 16.6 years) and FF2 (18-20 years of age; mean age 18.6 years).

Height and weight were used to calculate BMI (weight/ height ${ }^{2} ; \mathrm{kg} / \mathrm{m}^{2}$ ) at $2-4,5-7,15-17$ and $18-20$ years of age and participants were classified into weight classes: underweight (adult BMI $<18.5 \mathrm{~kg} / \mathrm{m}^{2}$ ), normal weight (adult BMI $\geq 18.5$ to $<25 \mathrm{~kg} / \mathrm{m}^{2}$ ), overweight (adult BMI $\geq 25$ to $<30 \mathrm{~kg} / \mathrm{m}^{2}$ ), and obese (adult BMI $\geq 30 \mathrm{~kg} / \mathrm{m}^{2}$ ). BMI reference values for every half-year and the International Obesity Taskforce (IOTF) age- and sex-specific cut-off values were used for children $2-18$ years of age. ${ }^{21}$ The WHO index for adults was used at age $>18$ years. ${ }^{22}$ Due to the small proportion of obesity at $2-4$ and $5-7$ years of age participants were also classified into the following weight classes: normal weight, light overweight (adult BMI $\geq 25$ to $<27 \mathrm{~kg} / \mathrm{m}^{2}$ ), and severe overweight/ obesity (adult BMI $\geq 27 \mathrm{~kg} / \mathrm{m}^{2}$ ). The childhood BMI variables were used as predictors in the analyses.

When used as an outcome, weight classes at 15-17 and 18-20 years of age were dichotomised as normal weight (adult BMI $<25 \mathrm{~kg} / \mathrm{m}^{2}$ ) or overweight/obesity (adult $\mathrm{BMI} \geq 25 \mathrm{~kg} / \mathrm{m}^{2}$ ).

Birth weight was divided into low $(<2500 \mathrm{~g})$, normal $(\geq 2500$ to $<4500 \mathrm{~g})$ and high birth weight $(\geq 4500 \mathrm{~g})$ according to the WHO definition. ${ }^{18}$ The ponderal index (PI) - birth weight $(\mathrm{kg})$ divided by the cube of birth length $(\mathrm{m})\left(\mathrm{kg} / \mathrm{m}^{3}\right)$-was divided into tertiles. Age- and sex-specific weight and BMI SD scores (SDS) were calculated using LMS coefficients corresponding to the Norwegian growth reference. ${ }^{23}$ Growth status at birth was categorised as small for gestational age $(<10$ th 
STUDY POPULATION

REASONS FOR EXCLUSION

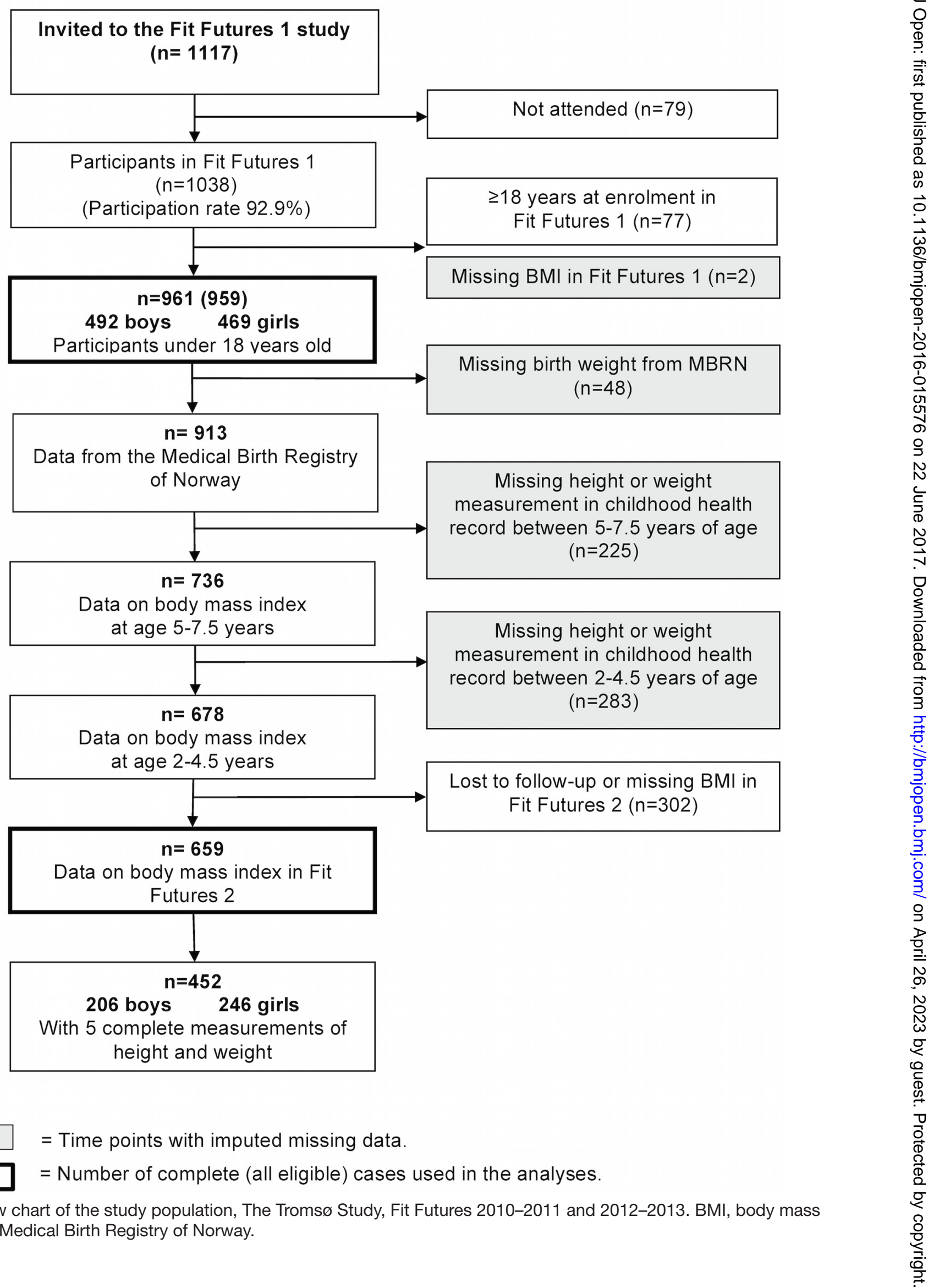

Figure 1 Flow chart of the study population, The Tromsø Study, Fit Futures 2010-2011 and 2012-2013. BMI, body mass index; MBRN, Medical Birth Registry of Norway. 
percentile), appropriate for gestational age, and large for gestational age ( $>90$ th percentile) based on birth weight and gestational age and according to a national reference standard of births in 1987-1998. ${ }^{24}$

Girls were categorised into three stages of pubertal maturation: early $(<12.5$ years), intermediate $(12.5-13.9$ years), and late ( $\geq 14.0$ years), based on age at menarche specified in self-administered questionnaires. Pubertal maturation in boys was classified as barely started, underway, and completed based on a validated self-reported measure. ${ }^{25}$

\section{Statistics}

Characteristics of the study population are presented as means and SD or numbers and percentages, by sex and weight class at 15-17 years of age. Differences between groups were assessed by t-test for continuous variables and by the $\chi^{2}$ test for categorical variables. Associations between BMI at different ages were assessed with Spearman's rank correlations.

Tracking of birth weight or childhood BMI and weight class into adolescence was estimated as odds ratios (ORs) for being overweight/obese in adolescence (15-17 and 18-20 years of age, as a combined endpoint). Generalised estimating equations (GEE) were used with a logit link function and an unstructured correlation matrix in crude and multivariable models. Predictors were birth weight (per 1-SD increase), birth weight SDS, PI in tertiles, BMI (per 1-SD increase), BMI SDS and weight class at 2-4 and 5-7 years of age. Covariates included in the multivariable models were gestational age/age, maternal age, and sex. All models were run in the total cohort and by sex. Covariates tested but not included in the final models were: multiple births, caesarean section, maternal disease or diabetes, time between measurements, and participation in FF2. Potential interaction between sex and birth weight or childhood BMI was assessed by including crossproduct terms in the models. Pubertal maturation was tested as a potential mediator. However, as it did not affect the coefficients and interaction terms were not significant, pubertal maturation was not included in the final models. Linearity was assessed by visual inspections of scatterplots, with birth weight and BMI as continuous variables (see online supplementary figures 1-3). No sign of a non-linear relationship was observed, but we analysed the predictors both as continuous and categorical variables.

Due to the relatively large number of missing explanatory variables, we performed multiple imputations on data that were missing at birth, 2-4 years and 5-7 years of age using chained equations generating 20 duplicate datasets. $^{2627}$ (see online supplementary document). The estimates from the 20 imputed datasets were combined into an overall estimate with corresponding SE using Rubin's rule. ${ }^{26} 27$

Multiple imputations and statistical analyses were carried out using Stata/MP 14.1 for Mac (Stata Corp, College Station, TX, USA). The level of statistical significance was set to two-sided $\mathrm{p}$ values $<0.05$.

\section{RESULTS}

Overall mean birth weight was $3530 \mathrm{~g}$ and the proportion of participants with high birth weight $(\geq 4500 \mathrm{~g})$ was $4.5 \%$. Characteristics of the study population at birth and at mean ages 2.6, 6.0, 16.6 and 18.6 years are presented by sex (table 1). The prevalence of overweight/obesity was $14.0 \%$ and $18.5 \%$ in girls, $8.8 \%$ and $10.9 \%$ in boys at 2-4 and 5-7 years of age, respectively. At 15-17 and 18-20 years of age, $20.6 \%$ and $20.9 \%$ of girls, and $23.4 \%$ and $28.0 \%$ of boys, were overweight/obese. The prevalence of obesity was $<1.5 \%$ at $2-4$ years and increased to $6.6 \%$ in girls and $8.1 \%$ in boys at $18-20$ years of age (table 2 ).

Of the study population, $47.0 \%$ (452) had five complete measurements. The imputed dataset and the observed-cases dataset were similar with respect to main characteristics and prevalence rates of overweight/ obesity. Comparisons between the datasets are presented in (see online supplementary tables 1-2). The distribution of missing childhood data between sexes and weight classes at 15-17 or 18-20 years of age is presented in (see online supplementary table 3 ).

We explored sex-specific differences in anthropometric measurements from birth throughout childhood between participants classified as normal weight and overweight/ obese at 15-17 years of age (table 3). Girls classified as overweight/obese at 15-17 years of age had higher mean birth weight $(158 \mathrm{~g}, \mathrm{p}<0.05)$ than their normal weight female counterparts. Differences in mean BMI and mean weight also increased with age both among girls and boys classified as overweight/obese at 15-17 compared with their normal weight counterparts. Mean differences in BMI were 0.84 and $2.28 \mathrm{~kg} / \mathrm{m}^{2}$ among girls and 0.48 and $1.61 \mathrm{~kg} / \mathrm{m}^{2}$ among boys at $2-4$ and $5-7$ years of age, respectively $(\mathrm{p}<0.05)$. Mean differences in weight were 1.0 and $3.8 \mathrm{~kg}$ among girls at $2-4$ years and $5-7$ years of age, respectively, and 0.3 and $2.7 \mathrm{~kg}$ among boys at $2-4$ years and 5-7 years of age, respectively (only significant for boys at age 5-7) (table 3).

PI at birth and BMI in childhood were positively $(\mathrm{p}<0.001)$ correlated with BMI in adolescence. Spearman's Rho between PI at birth and BMI at 15-17 and $18-20$ years of age were 0.13 and 0.12 , respectively. Corresponding values for BMI at age 2-4 were 0.32 and 0.26 , and for BMI at age 5-7 they were 0.57 and 0.51 . BMI at 15-17 years of age was highly correlated with BMI at $18-20$ years of age (Spearman's Rho 0.85; $\mathrm{p}<0.001$ ).

\section{Tracking analysis}

In multivariable GEE analyses, a 1-SD (586 g) increase in birth weight was associated with higher odds of overweight/obesity at 15-20 years of age (OR 1.25, 95\% CI 1.06 to 1.48). Infants in the highest tertile of birth weight had significantly higher odds of later overweight/ obesity compared with those in the lowest tertile, but not compared with the mid tertile (adjusted OR for highest vs lowest tertile of PI 1.56, 95\% CI 1.08 to 2.24) (table 4). Repeating the analysis with growth categories as a predictor gave results similar to those obtained with 
Table 1 Characteristics for girls and boys of the Fit Futures cohort at birth and four ages up to 18-20 years, The Tromsø Study, Fit Futures, observed cases ${ }^{*}$

\begin{tabular}{|c|c|c|c|c|c|c|c|}
\hline \multirow[b]{2}{*}{ Characteristics } & \multicolumn{3}{|l|}{ Girls } & \multicolumn{3}{|c|}{ Boys } & \multirow[b]{2}{*}{$p$ Value $^{\dagger}$} \\
\hline & $\mathbf{n}$ & Mean/\% & (SD) & $\mathbf{n}$ & Mean/\% & (SD) & \\
\hline \multicolumn{8}{|l|}{ Birth } \\
\hline Birth length $(\mathrm{cm})$ & 419 & 49.4 & (2.3) & 454 & 50.2 & (2.3) & $<0.001$ \\
\hline Gestational age (weeks) & 393 & 39.7 & $(1.8)$ & 430 & 39.6 & $(2.1)$ & 0.176 \\
\hline Ponderal index $\left(\mathrm{kg} / \mathrm{m}^{3}\right)$ & 419 & 28.73 & $(2.81)$ & 454 & 28.45 & $(2.75)$ & 0.141 \\
\hline Body mass index $\left(\mathrm{kg} / \mathrm{m}^{2}\right)$ & 419 & 14.19 & $(1.49)$ & 454 & 14.28 & $(1.52)$ & 0.338 \\
\hline Birth weight SDS ${ }^{\ddagger}$ & 443 & -0.58 & $(1.74)$ & 470 & -0.24 & $(1.32)$ & 0.001 \\
\hline Body mass index $\mathrm{SDS}^{\ddagger}$ & 419 & 0.06 & $(1.05)$ & 454 & -0.02 & $(1.04)$ & 0.265 \\
\hline High birth weight ( $\geq 4500 \mathrm{~g}$ ) & 11 & $2.5 \%$ & & 30 & $6.4 \%$ & & \\
\hline Size for gestational age: & 443 & & & 470 & & & 0.554 \\
\hline Small for gestational age & 49 & $11.1 \%$ & & 46 & $9.8 \%$ & & \\
\hline Appropriate for gestational age & 356 & $80.4 \%$ & & 375 & $79.8 \%$ & & \\
\hline Large for gestational age & 38 & $8.6 \%$ & & 49 & $10.4 \%$ & & \\
\hline Maternal age at birth & 443 & 28.4 & (5.3) & 441 & 28.1 & (5.3) & 0.995 \\
\hline \multicolumn{8}{|l|}{$2-4$ years of age } \\
\hline \multicolumn{8}{|l|}{$5-7$ years of age } \\
\hline Age (years) & 354 & 6.0 & $(0.4)$ & 384 & 6.1 & $(0.4)$ & 0.253 \\
\hline Height (cm) & 354 & 116.7 & $(5.3)$ & 384 & 118.3 & $(5.3)$ & $<0.001$ \\
\hline Weight $(\mathrm{kg})$ & 352 & 21.8 & $(3.8)$ & 384 & 22.2 & $(3.5)$ & 0.143 \\
\hline Body mass index $\left(\mathrm{kg} / \mathrm{m}^{2}\right)$ & 352 & 15.96 & $(2.04)$ & 384 & 15.82 & $(1.74)$ & 0.304 \\
\hline Weight SDS ${ }^{\ddagger}$ & 352 & 0.0004 & $(1.10)$ & 384 & 0.11 & $(1.02)$ & 0.162 \\
\hline Body mass index SDS ${ }^{\ddagger}$ & 352 & -0.06 & $(1.10)$ & 384 & -0.03 & $(0.98)$ & 0.616 \\
\hline \multicolumn{8}{|l|}{$15-17$ years of age } \\
\hline Age (years) & 469 & 16.6 & $(0.4)$ & 492 & 16.6 & $(0.4)$ & 0.325 \\
\hline Height (cm) & 467 & 164.9 & $(6.5)$ & 492 & 176.9 & $(6.7)$ & $<0.001$ \\
\hline Weight $(\mathrm{kg})$ & 467 & 60.9 & $(11.5)$ & 492 & 70.2 & $(14.4)$ & $<0.001$ \\
\hline Body mass index $\left(\mathrm{kg} / \mathrm{m}^{2}\right)$ & 467 & 22.39 & $(3.96)$ & 492 & 22.38 & $(4.17)$ & 0.952 \\
\hline Pubertal maturation, ${ }^{\S}$ girls: & 464 & & & - & - & - & \\
\hline Early (<12.5years) & 147 & $31.7 \%$ & & & & & \\
\hline Intermediate (12.5-13.9years) & 212 & $45.7 \%$ & & & & & \\
\hline Late ( $\geq 14.0$ years) & 105 & $22.6 \%$ & & & & & \\
\hline Pubertal maturation, §boys: & - & - & - & 387 & & & \\
\hline
\end{tabular}


Table 1 Continued

\begin{tabular}{llllllll}
\hline & Girls & \multicolumn{5}{l}{ Boys } \\
\cline { 2 - 7 } Characteristics & $\mathbf{n}$ & Mean/\% & (SD) & $\mathbf{n}$ & Mean/\% & (SD) & $\mathrm{p} \mathrm{Value}^{\dagger}$ \\
\hline Barely started (PDS 2.0-2.9) & & & & 69 & $17.8 \%$ & & \\
$\quad$ Underway (PDS 3.0-3.9) & & & & 285 & $73.6 \%$ & \\
$\quad$ Completed (PDS 4.0) & & & & 33 & $8.5 \%$ & & \\
18-20years of age & & & & & & & \\
Age (years) & 363 & 18.6 & $(0.4)$ & 296 & 18.7 & $(0.3)$ & 0.105 \\
Height (cm) & 363 & 165.7 & $(6.5)$ & 296 & 179.1 & $(6.5)$ & $<0.001$ \\
Weight (kg) & 363 & 63.2 & $(12.0)$ & 296 & 75.2 & $(14.6)$ & $<0.001$ \\
Body mass index $\left(\mathrm{kg} / \mathrm{m}^{2}\right)$ & 363 & 23.02 & $(4.22)$ & 296 & 23.42 & $(4.18)$ & 0.228 \\
\hline
\end{tabular}

*In observed data $\mathrm{n}$ is varying from 659 to 961.

$\mathrm{tp}$ Value for sex difference was obtained by t-test or $\chi^{2}$ test.

†SDS, SD scores according to Norwegian reference data. ${ }^{23}$

§Pubertal maturation is based on age of menarche in girls and according to Pubertal Development Scale (PDS) in boys; total score of four items of secondary sexual characteristics on a scale from 1 to 4 (sum of total score divided by 4 ). None had a score $<2.0$ in total score. ${ }^{25}$

GA, gestational age.

PI in tertiles. In adjusted analyses, being small for gestational age was associated with lower odds of overweight/ obesity at 15-20 years of age compared with those appropriate for gestational age (OR $0.40,95 \%$ CI 0.22 to 0.72 ). Infants large for gestational age did not have significantly higher odds of overweight/obesity compared with those appropriate for gestational age (adjusted OR for large vs. appropriate for gestational age $1.31,95 \%$ CI 0.84 to 2.05) (data not shown).

Childhood BMI was associated with overweight/obesity in adolescence (OR per 1-SD increase in BMI at age 2-4: $1.66,95 \%$ CI 1.40 to 1.96 ; OR per 1-SD increase in BMI at age 5-7: $3.23,95 \%$ CI 2.56 to 4.07 ). Children who were obese at 2-4 years of age had fivefold increased odds of becoming overweight/obese in adolescence (OR $5.35,95 \%$ CI 1.42 to 20.09) compared with their normal weight peers, while at $5-7$ years of age the estimated OR was 15.59 (95\% CI 6.60 to 36.85 ), compared with those of normal weight. Cross-product terms between sex and birth weight/BMI were tested and no significant interaction was found (table 4).

Due to the small number of obese children, CIs were wide for these groups. Therefore additional analyses were performed with weight class in three groups as predictor. At 2-4 years of age, those with light overweight (adult BMI $\geq 25$ to $<27 \mathrm{~kg} / \mathrm{m}^{2} \quad(\mathrm{n}=52)$ ) had an OR of 1.88 (95\% CI 1.08 to 3.29) and those with severe overweight/obesity (adult BMI $\geq 27 \mathrm{~kg} / \mathrm{m}^{2}$ $(\mathrm{n}=25))$ had an OR of 3.01 (95\% CI 1.47 to 6.18 ) for overweight/obesity at 15-20 years of age, compared with those of normal weight. At 5-7 years of age the corresponding ORs were 4.96 (95\% CI 2.82 to 8.73) for light overweight $(\mathrm{n}=48)$ and 11.51 (95\% CI 6.63 to 19.99$)$ for severe overweight/obesity $(n=59)$ when

Table 2 Weight classes* at four ages, The Tromsø Study, Fit Futures observed cases†

\begin{tabular}{|c|c|c|c|c|c|c|c|c|c|}
\hline & \multirow[t]{2}{*}{ Age } & \multicolumn{2}{|c|}{ 2-4 years } & \multicolumn{2}{|c|}{$5-7$ years } & \multicolumn{2}{|c|}{$15-17$ years } & \multicolumn{2}{|c|}{ 18-20years } \\
\hline & & $\mathbf{n}$ & $\%$ & $\mathbf{n}$ & $\%$ & $\mathbf{n}$ & $\%$ & $\mathrm{n}$ & $\%$ \\
\hline \multirow[t]{5}{*}{ Girls } & Underweight & 48 & 14.6 & 37 & 10.5 & 24 & 5.1 & 16 & 4.4 \\
\hline & Normal weight & 234 & 71.3 & 250 & 71.0 & 347 & 74.3 & 271 & 74.7 \\
\hline & Overweight & 41 & 12.5 & 49 & 13.9 & 70 & 15.0 & 52 & 14.3 \\
\hline & Obesity & 5 & 1.5 & 16 & 4.6 & 26 & 5.6 & 24 & 6.6 \\
\hline & Total & 328 & 100.0 & 352 & 100.0 & 467 & 100.0 & 363 & 100.0 \\
\hline \multirow[t]{5}{*}{ Boys } & Underweight & 43 & 12.3 & 28 & 7.3 & 38 & 7.7 & 24 & 8.1 \\
\hline & Normal weight & 276 & 78.9 & 314 & 81.8 & 339 & 68.9 & 189 & 63.9 \\
\hline & Overweight & 27 & 7.7 & 27 & 7.0 & 79 & 16.1 & 59 & 19.9 \\
\hline & Obesity & 4 & 1.1 & 15 & 3.9 & 36 & 7.3 & 24 & 8.1 \\
\hline & Total & 350 & 100.0 & 384 & 100.0 & 492 & 100.0 & 296 & 100.0 \\
\hline
\end{tabular}

*Weight classes according to the International Obesity Taskforce (IOTF) age- and sex-specific cut-off values for children 2-18 years of age and the $\mathrm{WHO}$ index for adults from age 18-20. ${ }^{21} 22$

†ln observed cases $\mathrm{n}$ is varying at different ages from 659 to 959. 


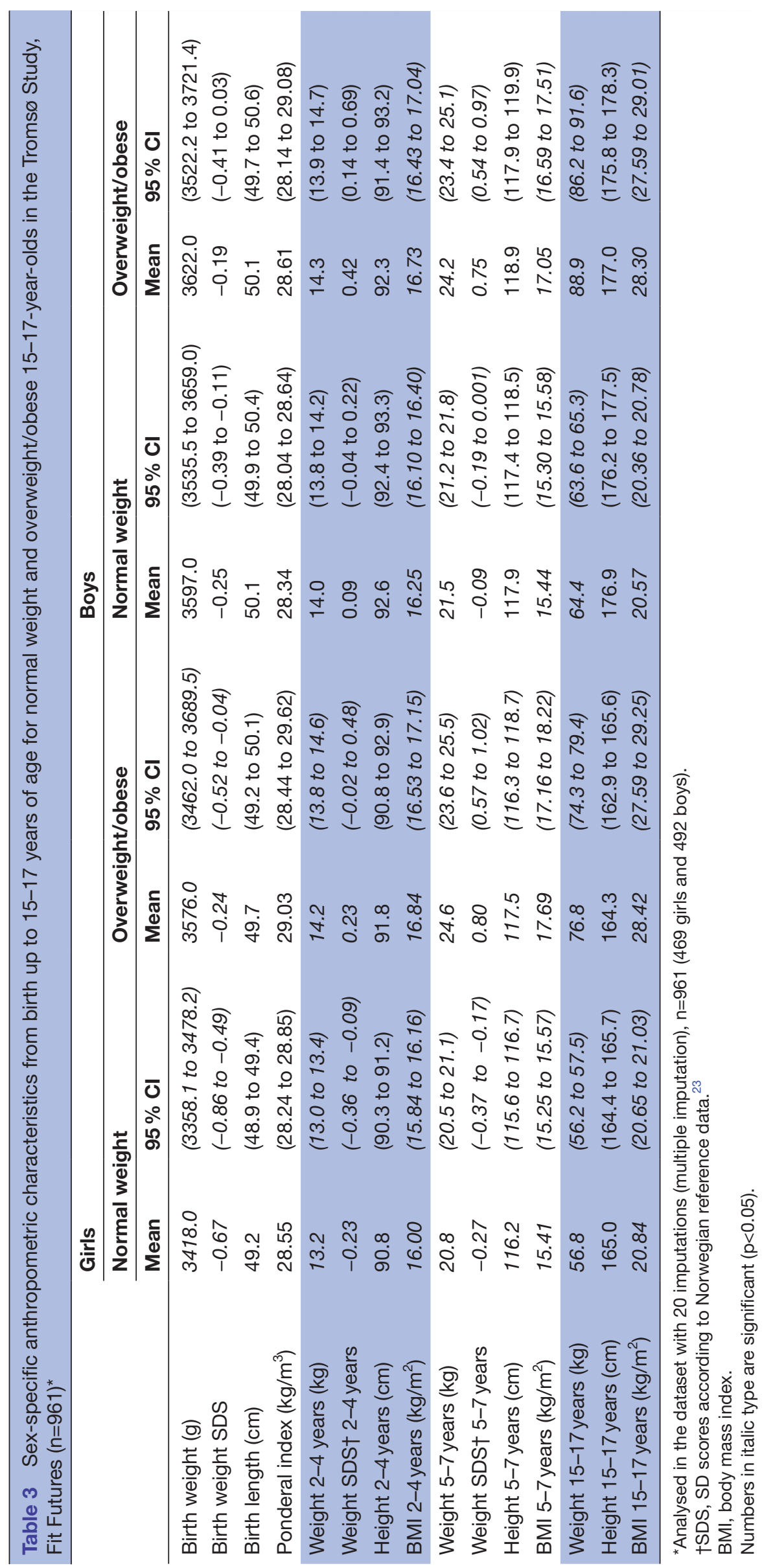




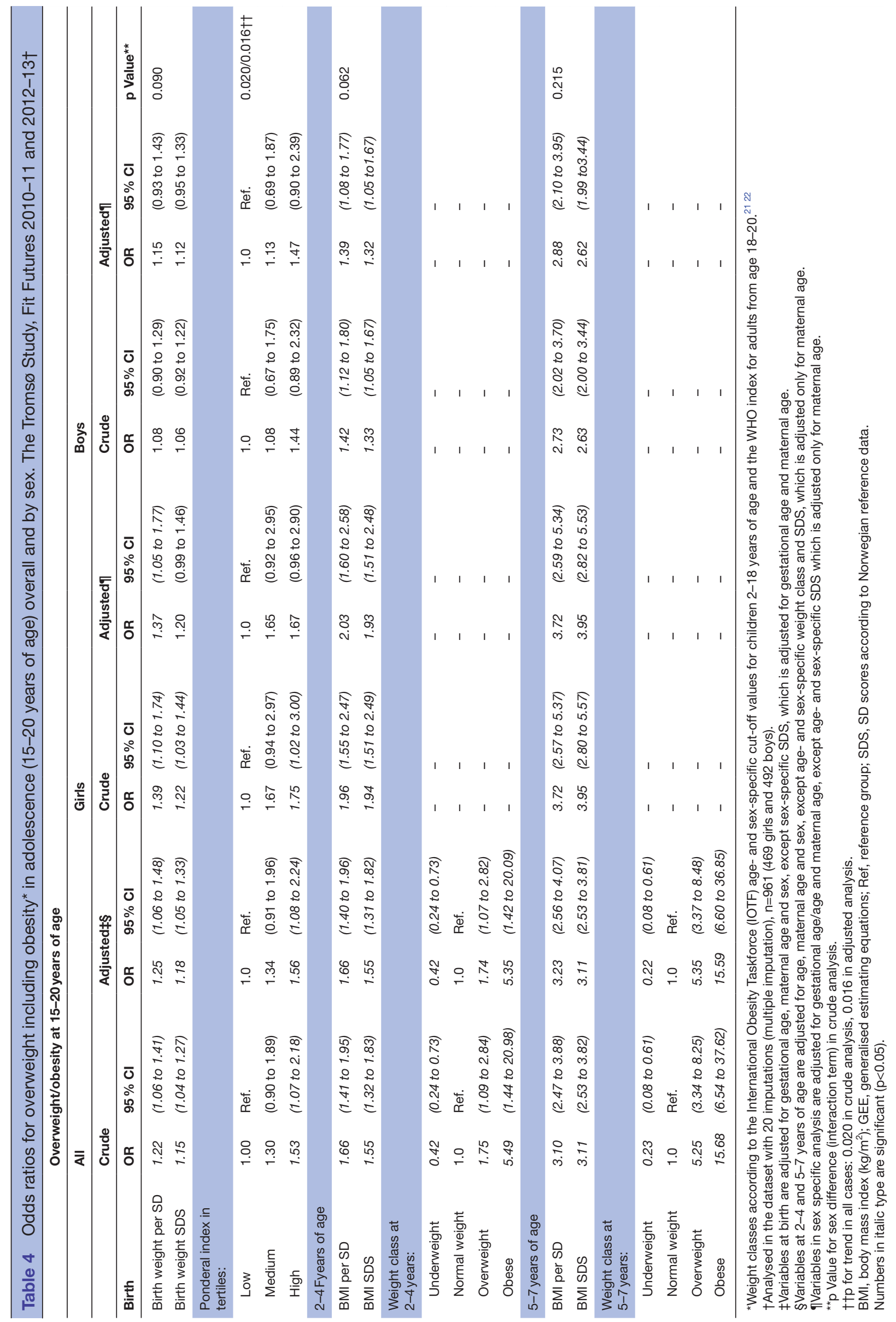


compared with those of normal weight (data not shown).

\section{DISCUSSION}

In this population-based longitudinal study of Norwegian adolescents born in 1992-1994, we found a statistically significant, but modest, association between birth weight and overweight/obesity at 15-20 years of age. Tracking of BMI and overweight from childhood to adolescence was moderate. Children with more severe overweight/ obesity had considerably higher odds of later overweight/ obesity compared with those with light overweight or their normal weight peers. The prevalence of overweight/obesity increased with age. More girls than boys were overweight/obese at 2-4 and 5-7 years of age, but at 15-20 years this shifted so that more boys than girls were overweight/obese. Tracking of overweight/obesity from birth and childhood into adolescence was generally stronger in girls than in boys; however, no significant interaction with sex was found.

Mean birth weight and the proportion with high birth weight $(4.5 \%)$ were somewhat higher than national data from 1992 to 1994 birth records (3.7-4.2\%). ${ }^{18}$ High mean birth weight and high prevalence rates of overweight/obesity in children have been reported from the northernmost region of Norway. ${ }^{18} 28$ The prevalence of overweight/obesity in childhood we observed was comparable with findings from other studies from Norway that included similar age groups ${ }^{1329}$; however, the prevalence of overweight/obesity in adolescence was higher than figures from comparable Norwegian studies. ${ }^{29} 30$ The prevalence of overweight/obesity is generally lower in the Nordic countries compared with the USA and southern European countries, which was reflected in our study. ${ }^{31-33}$

Birth weight as a risk factor for overweight/obesity at later ages has been extensively studied with varying results. ${ }^{10} 1134$ In the review by Brisbois et al 25 of 43 studies found an association between birth weight and adult BMI or overweight/obesity, but with no clear conclusion that birth weight was an early marker for adult overweight/obesity. ${ }^{10}$ Six of seven studies in a review by Weng et al found significant and strong associations between high birth weight and childhood overweight. ${ }^{34}$ In two recent studies from Norway, increased BMI SDS at birth was associated with overweight including obesity at 8 years of age (OR per 1-SDS increase in BMI at birth $1.8,95 \%$ CI 1.6 to 2.0$).{ }^{12}$ A moderate degree of tracking of body size from birth to 7 years of age was found in the Norwegian Mother and Child Cohort Study. ${ }^{13}$ Our finding of a statistically significant association between birth weight and overweight/obesity in adolescence is in line with these studies. However, birth weight was only a modest predictor of later overweight/obesity in our study, probably due to the longer timespan. Stronger tracking of overweight/obesity over a shorter timespan has been reported. ${ }^{121334}$ In contrast to our findings, two newer population-based studies from Sweden, which were comparable to our study, did not find high birth weight to be associated with high BMI or obesity at 15 or 20 years of age. ${ }^{35}$ Since tracking coefficients are influenced by time, comparisons between studies are challenging. 837

The participants in our study were born in a period during which there was a higher mean birth weight in the Norwegian population. The percentage of infants with a birth weight over $4500 \mathrm{~g}$ increased in Norway from 1990 to 2000 , before declining to the same level as in $1990 .^{18}$ If birth weight emerged as a strong predictor of later overweight/obesity, one would expect to see a high degree of tracking in our study compared with studies of children with a lower mean birth weight, but the estimated tracking coefficients were only moderate. However, since the prevalence of overweight/obesity in adolescence is relatively high in our study population, a birth cohort effect cannot be ruled out.

Among those classified as overweight/obese at 15-17 years of age, mean weight was generally higher at birth and BMI was significantly higher at 2-4 years of age. The estimated tracking coefficients from 2-4 and 5-7 years of age were moderate among our overweight participants and stronger among those classified with severe overweight/obesity. Our findings are in line with previous results from this cohort, as well as other studies and reviews. 679353839 Birth weight or BMI/overweight at 2-4 years of age were not strong predictors of later overweight/obesity; BMI/weight class at 5-7 years of age were stronger predictors. Others have also observed a stronger degree of tracking from 5 to 6 years of age, especially among subjects classified as obese. ${ }^{32} 353639$

Weight status can fluctuate throughout childhood, ${ }^{32}$ and we observed this in our study population. ${ }^{38}$ The proportion of those with a high birth weight $(>4500 \mathrm{~g}$ ) that were overweight/obese at later ages varied between 17-34\%; it was lowest at 5-7 years of age and highest in adolescence. The proportion of infants with a normal birth weight that were classified as overweight/obese at later ages were 10-24\%; this proportion was lowest at 2-4 years of age and highest in adolescence (data not shown).

The IOTF reference for BMI classification has low sensitivity but high specificity compared with other references. ${ }^{2133}$ Hence, the estimated prevalence of overweight/ obesity based on the IOTF reference may be too low and could influence the predictive ability of the classification. On the other hand, a Swedish study comparing different references concluded that the IOTF reference would identify the fewest false positive cases. ${ }^{33}$ We also calculated weight and BMI SDS based on the Norwegian reference population. ${ }^{23}$ Mean weight SDS at 2-4 and 5-7 years of age was higher; however, mean BMI SDS was comparable to the reference population. ${ }^{23}$ GEE analyses give a population-averaged estimate, which generally gives lower and valid estimates when the outcome is dichotomous. ${ }^{40} \mathrm{We}$ therefore consider the estimated tracking coefficients in our study to be representative of Norwegian children.

The strengths of this study are the population-based design of the Fit Future study and a high attendance rate, which minimise selection bias. In this region more 
than $90 \%$ of the population in the age group 16-19 years attend upper-secondary school (an entitlement in Norway). Birth variables from the MBRN and measured height and weight data at all ages assures good compliance and good quality data, which limits the risk of information bias. We have longitudinal data over a relatively long time-span from birth in the 1990s up to 18-20 years of age. This study brings updated data on tracking of overweight and obesity from a representative sample of Norwegian children and adolescents. The prevalence of overweight/obesity at 15-20 years of age may not be a representative estimate for the entire Norwegian adolescent population or populations of different ethnicities. However, the associations found in the tracking analysis are considered to be comparable to other populations with similar characteristics.

The main limitation of this study was the missing data. The percentage of missing main variables from childhood did not differ between sexes or weight classes in adolescence (see online supplementary table 3). More boys than girls were missing at FF2 and we cannot rule out that they were not missing at random. ${ }^{26}$ This leads to some uncertainty in the estimated prevalence of overweight/ obesity in childhood and at 18-20 years of age. However, analysis of the imputed dataset, the observed-cases dataset and only complete-cases dataset, all gave similar results. A recognised method was used to impute the missing childhood values. ${ }^{27}$ Mean values were generally lower after imputation, compared with observed cases, but differences were small (see online supplementary table 1 and table 2). Childhood height and weight data are obtained from different health clinics and an overestimation of overweight/obesity due to instrument error might occur. ${ }^{41}$ However, potential misclassification bias is assumed to be non-differential. Factors known to affect overweight/obesity, such as maternal BMI, smoking habits, and socioeconomic status, were not registered in the MBRN for these children. ${ }^{10}$ Nor did we have access to information on lifestyle factors from childhood, and the effect of these potential confounding factors cannot be excluded. BMI is a simple measure of obesity and does not separate between fat and muscle mass, although it is widely used in clinical practice and research. BMI in children varies with growth and results need to be interpreted with some caution. ${ }^{6}$ More sophisticated measures of body composition would give better measures of adiposity, which is more strongly linked to disease risk in adulthood. Unfortunately, such data were not available for the present study.

Several researchers have recommended early intervention and prevention efforts, some starting even before conception. ${ }^{1} 101114$ 'The first 1000 days' are suggested as a critical early-life period. ${ }^{11}$ Treatment of obesity among children/adolescents is challenging, which is why establishing healthy habits early in life is of the utmost importance. ${ }^{114} 17$ We aimed to shed light on the most appropriate age to start risk-based preventive efforts. Our findings do not indicate that most children at risk can be identified already at birth or at 2-4years of age. However, children with more severe overweight/obesity and a high risk of later overweight/obesity could be identified before 5-7 years of age. Development of overweight/obesity is complex; it involves genetic and multiple environmental factors and is still not fully understood. ${ }^{1516}$ Since genetic factors can explain $40-75 \%$ of BMI variation in childhood and adolescence, ${ }^{16}$ some degree of tracking is probably inevitable. Strong positive associations have been seen between parents and their adolescent offspring's BMI. ${ }^{42}$ Identifying children at risk of later overweight/obesity requires a family approach. The influential role of genetic factors varies with age ${ }^{16}$ and may be prevented by behavioural changes. ${ }^{15}$ Prevention of overweight/obesity therefore requires efforts tailored at addressing parents and children at different ages. More research is needed into preventive and treatment programmes for families and children at different ages.

\section{SUMMARY AND CONCLUSION}

Birth weight did not have a strong influence on overweight/obesity at 15-20 years of age. Tracking of BMI from early childhood to late adolescence was moderate. Severe overweight/obesity at $2-4$ and $5-7$ years of age was a strong predictor of later overweight/obesity. However, the prevalence of overweight/obesity increased with age. Prevention efforts should therefore address children of all ages.

\section{Author affiliations}

${ }^{1}$ Department of Clinical Research, University Hospital of North Norway, Troms $\emptyset$, Norway

${ }^{2}$ Department of Health and Care Sciences, Faculty of Health Sciences, UiT The Arctic University of Norway, Troms $\emptyset$, Norway

${ }^{3}$ Department of Paediatrics, Finnmark Hospital Trust, Hammerfest, Norway

${ }^{4}$ Paediatric Research Group, Faculty of Health Sciences, UiT The Arctic University of Norway, Troms $\emptyset$, Norway

${ }^{5}$ Department of Community Medicine, Faculty of Health Sciences, UiT The Arctic University of Norway, Troms $\emptyset$, Norway

${ }^{6}$ Department of Microbiology and Infection Control, University Hospital of North Norway, Troms $\emptyset$, Norway

Correction notice This paper has been amended since it was published Online First. Owing to a scripting error, some of the publisher names in the references were replaced with 'BMJ Publishing Group'. This only affected the full text version, not the PDF. We have since corrected these errors and the correct publishers have been inserted into the references.

Acknowledgements The authors thank the participants in the Fit Futures study for their contribution. We thank the public health nurses; Britt Simonsen, Hilde Valø, Birgit Iversen, Hege Johansen and Verna Rothenpieler in Troms $\emptyset$, Lyngen, Balsfjord, Karlsøy and Storfjord municipalities, for facilitating part of the data collection in this study. We thank Sissel Andersen and Anna Kirsti Kvitnes at the Department of Community Medicine, Faculty of Health Sciences, UiT The Arctic University of Norway, and the staff at the Clinical Research Department, University Hospital of North Norway, for their help with the data collection in the Fit Futures study. We wish to acknowledge the services of the MBRN. Finally, we thank the board of The Troms $\emptyset$ Study.

Contributors ASF, NE and AK contributed to the conception, study design and data acquisition of the Fit Futures study. ASF is the principal investigator of the Fit Futures study. EE, NE and GS contributed to the conception, design, data collection, analyses and interpretation of data, as well as drafting the manuscript in the present study. EE performed the statistical analyses. TW gave advice on statistical analysis and especially revised the manuscripts method and result sections. All authors have contributed substantially in interpretation of data and critically 
revising the manuscript. All authors have read and approved the final submitted manuscript.

Funding This work was supported by a grant from the Northern Norway Regional Health Authority (grant number SFP1226- 15). The publication charges for this article have been funded by a grant from the publication fund of UiT The Arctic University of Norway.

Competing interests None declared.

Patient consent Obtained.

Ethics approval The Troms $\emptyset$ Study, Fit Futures was approved by the Norwegian Data Protection Authority (reference number 2009/1282) and the Regional Committee for Medical and Health Research Ethics, North Norway (REK nord) approved Fit Futures 1 and 2 and the present study (Reference number: 2014/1397/ REK nord).

Provenance and peer review Not commissioned; externally peer reviewed.

Data sharing statement The data set may be accessible by application to the scientific board of The Troms $\emptyset$ Study.

Open Access This is an Open Access article distributed in accordance with the Creative Commons Attribution Non Commercial (CC BY-NC 4.0) license, which permits others to distribute, remix, adapt, build upon this work non-commercially, and license their derivative works on different terms, provided the original work is properly cited and the use is non-commercial. See: http://creativecommons.org/ licenses/by-nc/4.0/

(C) Article author(s) (or their employer(s) unless otherwise stated in the text of the article) 2017. All rights reserved. No commercial use is permitted unless otherwise expressly granted.

\section{REFERENCES}

1. Ebbeling CB, Pawlak DB, Ludwig DS. Childhood obesity: publichealth crisis, common sense cure. Lancet 2002;360:473-82.

2. Ayer J, Charakida M, Deanfield JE, et al. Lifetime risk: childhood obesity and cardiovascular risk. Eur Heart J 2015;36:1371-6.

3. Twig G, Yaniv $\mathrm{G}$, Levine $\mathrm{H}$, et al. Body-mass index in 2.3 million adolescents and cardiovascular death in adulthood. N Engl J Med 2016;374:2430-40.

4. Reilly JJ, Kelly J. Long-term impact of overweight and obesity in childhood and adolescence on morbidity and premature mortality in adulthood: systematic review. Int J Obes 2011;35:891-8.

5. Park $\mathrm{MH}$, Falconer $\mathrm{C}$, Viner RM, et al. The impact of childhood obesity on morbidity and mortality in adulthood: a systematic review. Obes Rev 2012;13:985-1000.

6. Simmonds M, Burch J, Llewellyn A, et al. The use of measures of obesity in childhood for predicting obesity and the development of obesity-related diseases in adulthood: a systematic review and meta-analysis. Health Technol Assess 2015;19:1-336.

7. Ziyab AH, Karmaus W, Kurukulaaratchy RJ, et al. Developmental trajectories of body mass index from infancy to 18 years of age: prenatal determinants and health consequences. J Epidemiol Community Health 2014;68:934-41.

8. Twisk JW, Kemper HC, van Mechelen W, et al. Tracking of risk factors for coronary heart disease over a 14-year period: a comparison between lifestyle and biologic risk factors with data from the Amsterdam Growth and Health Study. Am J Epidemiol 1997;145:888-98.

9. Singh AS, Mulder C, Twisk JW, et al. Tracking of childhood overweight into adulthood: a systematic review of the literature. Obes Rev 2008;9:474-88.

10. Brisbois TD, Farmer AP, McCargar LJ. Early markers of adult obesity: a review. Obes Rev 2012;13:347-67.

11. Woo Baidal JA, Locks LM, Cheng ER, et al. Risk factors for childhood obesity in the first 1,000 days: a systematic review. Am J Prev Med 2016;50:761-79.

12. Glavin $\mathrm{K}$, Roelants $\mathrm{M}$, Strand $\mathrm{BH}$, et al. Important periods of weight development in childhood: a population-based longitudinal study. BMC Public Health 2014;14:160.

13. Kristiansen AL, Bjelland M, Brantsæter AL, et al. Tracking of body size from birth to 7 years of age and factors associated with maintenance of a high body size from birth to 7 years of age-the Norwegian Mother and Child Cohort study (MoBa). Public Health Nutr 2015;18:1746-55.

14. Gillman MW, Ludwig DS. How early should obesity prevention start? N Engl J Med 2013;369:2173-5.
15. Huang T, Hu FB. Gene-environment interactions and obesity: recent developments and future directions. BMC Med Genomics 2015;8(Suppl 1)2.

16. Silventoinen K, Jelenkovic A, Sund R, et al. Genetic and environmental effects on body mass index from infancy to the onset of adulthood: an individual-based pooled analysis of 45 twin cohorts participating in the Collaborative project of development of anthropometrical measures in twins (CODATwins) study. Am J Clin Nutr 2016;104:371-9.

17. Danielsson P, Kowalski J, Ekblom Ö, et al. Response of severely obese children and adolescents to behavioral treatment. Arch Pediatr Adolesc Med 2012;166:1103-6.

18. Norwegian Institute of Public Health. Birth weight in Norway, fact sheet: Norwegian Institute of Public Health. 2015 https://www.fhi. no/hn/statistikk/statistikk3/fodselsvekt-i-norge-faktaark/ (updated 07.12.2015; cited 06.09.2016).

19. Winther A, Dennison E, Ahmed LA, et al. The Tromsø study: fit futures: a study of Norwegian adolescents' lifestyle and bone health. Arch Osteoporos 2014;9:185

20. Sørensen M, Wickman M, Sollid JU, et al. Allergic disease and Staphylococcus aureus carriage in adolescents in the Arctic region of Norway. Pediatr Allergy Immunol 2016;27:728-35.

21. Cole TJ, Lobstein T. Extended international (IOTF) body mass index cut-offs for thinness, overweight and obesity. Pediatr Obes 2012;7:284-94.

22. World Health Organization. Obesity: preventing and managing the gobal epidemic. Report of a WHO consultation. WHO technical report series. Geneva, Switzerland: World Health Organization, 1997.

23. Júlíusson PB, Roelants M, Nordal E, et al. Growth references for 0-19 year-old Norwegian children for length/height, weight, body mass index and head circumference. Ann Hum Biol 2013;40:220-7.

24. Skjaerven R, Gjessing HK, Bakketeig LS. Birthweight by gestational age in Norway. Acta Obstet Gynecol Scand 2000;79:440-9.

25. Petersen AC, Crockett L, Richards M, et al. A self-report measure of pubertal status: reliability, validity, and initial norms. J Youth Adolesc 1988;17:117-33.

26. White IR, Royston P, Wood AM. Multiple imputation using chained equations: issues and guidance for practice. Stat Med 2011;30:377-99.

27. Stata. Multiple-Imputation reference manual (program). Release 14 version. College Station, Texas: A Stata Press Publication, StataCorp LP, 2015.

28. Norwegian Institute of Public Health. 2016. Children's Health and the Environment - Risk and Health-Promoting Factors - Annual Report 2016. Oslo, Norway: Norwegian Institute of Public Health. 94: 51-58.

29. Júlíusson PB, Eide GE, Roelants M, et al. Overweight and obesity in Norwegian children: prevalence and socio-demographic risk factors. Acta Paediatr 2010;99.

30. Bratberg GH, Nilsen TI, Holmen TL, et al. Early sexual maturation, central adiposity and subsequent overweight in late adolescence. a four-year follow-up of 1605 adolescent Norwegian boys and girls: the Young HUNT study. BMC Public Health 2007;7:1-7.

31. Wijnhoven TM, van Raaij JM, Spinelli A, et al. WHO European Childhood Obesity Surveillance Initiative 2008: weight, height and body mass index in 6-9-year-old children. Pediatr Obes 2013;8:79-97.

32. Cunningham SA, Kramer MR, Narayan KM. Incidence of childhood obesity in the United States. N Engl J Med 2014;370:403-11.

33. Brann E, Sjöberg A, Chaplin JE, et al. Evaluating the predictive ability of childhood body mass index classification systems for overweight and obesity at 18 years. Scand J Public Health 2015;43:802-9.

34. Weng SF, Redsell SA, Swift JA, et al. Systematic review and metaanalyses of risk factors for childhood overweight identifiable during infancy. Arch Dis Child 2012;97:1019-26.

35. Fåhraeus $\mathrm{C}$, Wendt LK, Nilsson M, et al. Overweight and obesity in twenty-year-old Swedes in relation to birthweight and weight development during childhood. Acta Paediatr 2012;101:637-42.

36. Angbratt M, Ekberg J, Walter L, et al. Prediction of obesity from infancy to adolescence. Acta Paediatr 2011;100:1249-52

37. Twisk JW. The problem of evaluating the magnitude of tracking coefficients. Eur J Epidemiol 2003;18:1025-6.

38. Evensen E, Wilsgaard T, Furberg A-S, et al. Tracking of overweight and obesity from early childhood to adolescence in a populationbased cohort - the Tromsø Study, Fit Futures. BMC Pediatr 2016;16:1-11.

39. Johannsson E, Arngrimsson SA, Thorsdottir I, et al. Tracking of overweight from early childhood to adolescence in cohorts born 
1988 and 1994: overweight in a high birth weight population. Int $J$ Obes 2006;30:1265-71.

40. Twisk JWR. Applied longitudinal data analysis for epidemiology. $A$ practical guide. 2nd edition. Cambridge, UK: Cambridge University Press, 2013:119-39.
41. Biehl A, Hovengen R, Meyer HE, et al. Impact of instrument error on the estimated prevalence of overweight and obesity in populationbased surveys. BMC Public Health 2013;13:146.

42. Næss $\mathrm{M}$, Holmen $\mathrm{TL}$, Langaas $\mathrm{M}$, et al. Intergenerational transmission of overweight and obesity from parents to their adolescent offspring The HUNT study. PLoS One 2016;11:e0166585. 